\title{
Experimental Study on T-shaped Joints Composed of Plaster-Concrete Compound Panels
}

\author{
Shaochun Ma ${ }^{1}$ and Nan Jiang ${ }^{1,2, *}$ \\ 1 School of Civil Engineering, Tianjin University, Tianjin 300072, China; mashaochun2627@126.com \\ 2 Key Laboratory of Coastal Civil Engineering Structure and Safety (Tianjin University), \\ Ministry of Education, Tianjin 300072, China \\ * Correspondence: jiangnan@tju.edu.cn; Tel.: +86-138-2074-1249
}

Received: 7 April 2016; Accepted: 26 April 2016; Published: 2 May 2016

\begin{abstract}
A hidden concrete column was built at the core of the T-shaped joints composed of plasterconcrete compound panels in order to study their earthquake resistant behavior. In this paper, earthquake resistance tests were performed on two types of composite T-shaped joints, six samples in total, in which the horizontal steel bars were embedded and not embedded in their core, to analyze the mechanical deformation, cracking, hysteretic behavior, ductility, and stiffness degeneration of the composite T-shaped joints as well as their energy dissipation properties such as damping coefficient, energy dissipation coefficient, and power ratio coefficient. The two types of composite joints composed of interior and exterior compound walls were found to have good mechanical properties. A comparison of the various indicators for the two types of T-shaped joints revealed that embedding the horizontal steel bars embedded in the web and flange of the T-shaped joints in their core can help improve the earthquake resistance and energy dissipation properties of the composite T-shaped joints.
\end{abstract}

Keywords: compound walls; specially shaped column; T-shaped joints; tests; energy dissipation; cracks

\section{Introduction}

In recent years, vigorously developing green buildings has been a common concern for people around the world due to environmental pollution and energy shortage. China has actively developed green and low-carbon buildings [1] in order to achieve the goal of new urban buildings saving up to $65 \%$ energy by 2020, and has made gradual energy-saving transformation of existing buildings [2]. Building energy-saving technology is primarily reflected by the functions of building envelopes (walls, roofs, floors, doors, and windows, etc.) and the low energy consumption of heating systems. Investigation finds that to save energy in terms of walls is the most direct, economical, and effective measure. However, traditional wall materials not only pollute the environment, but also consume a considerable amount of energy. Therefore, actively promoting innovation in wall materials by looking for energy-efficient, low-cost, and green wall materials represents a challenge for researchers.

Building plaster, which is a common green cementing material, is often used in building panels [3]. Natural gypsum and industrial gypsum are partially dehydrated to form the plaster which is primarily composed of $\beta-\mathrm{CaSO}_{4} \bullet 1 / 2 \mathrm{H}_{2} \mathrm{O}$, namely the building plaster often found in engineering. The density and compressive strength is $13.0 \sim 14.5 \mathrm{kN} / \mathrm{m}^{3}, 5 \sim 10 \mathrm{MPa}$, respectively [4]. Gypsum, which is light, cheap, and pollution free, serves as a good fireproof material, with a thermal conductivity generally being $0.3 \mathrm{~W} / \mathrm{Mk}$ [5]. The many pores existing in gypsum enables gypsum to exhibit good thermal insulation properties. During the production of plaster, retarders can be added to control its setting speed in order to achieve good construction effects.

With the constant development of building materials, various fibers have also been used in the construction field. Due to its good tensile resistance, sound insulation, heat resistance, corrosion resistance, and insulation properties, fiberglass is often used as a reinforcing material in building 
compound materials. It can form a perfect combination with plaster or concrete interfaces, help improve the strain and toughness properties of plaster-concrete compound materials, and effectively prevent the formation and evolution of small cracks [6]. The use of gypsum and fiberglass in the construction field is expected to facilitate the development of green buildings and new buildings.

Therefore, fiberglass, various chemical admixtures, a small amount of cement, and a certain amount of water can be added to gypsum to make plaster panels with good mechanical properties. Currently, these kinds of plaster panels are primarily produced by machines in factories to make interior or exterior walls. They have dimensions of $12000 \mathrm{~mm} \times 3050 \mathrm{~mm} \times 120 \mathrm{~mm}$ with sectional dimensions of the cavities of $94 \mathrm{~mm} \times 230 \mathrm{~mm}$. Plaster panels are mainly characterized by being energy saving, environmentally friendly, low carbon, heat insulated, soundproof, light, and easy to process. Thermal insulation boards and pure plaster panels can be attached to the outside of plaster panels to make special integrated plaster panels for exterior walls. Concrete can be poured into the cavities of interior and exterior plaster panels to make interior and exterior compound panels. In order to gain more knowledge of the mechanical properties of interior and exterior plaster based walls or find a design most conducive to their mechanical properties, a lot of scholars around the world have conducted extensive experimental studies [7-12] and obtained some valuable results. However, the majority of these studies have focused on separate compound panels, relatively few of them on the joints composed of compound panels in which the plaster panels are only vertically holed [13-14], and fewer of them on the connection between T-shaped joints composed of plaster-based compound panels with vertically and horizontally holed plaster panels and the hidden specially shaped concrete columns at their cores.

In this paper, earthquake resistance tests are performed on the T-shaped joints composed of interior and exterior compound panels with a hidden specially shaped (T-shaped) column as the connector in strict accordance with the requirements of the specifications relating to earthquake resistance tests. The mechanical deformation, cracking, failure modes, hysteretic behavior, ductility, stiffness degeneration, and material strain of the composite T-shaped joint samples as well as their energy dissipation properties such as damping coefficient, energy dissipation coefficient, and power ratio coefficient are studied in detail. The performance of the hidden T-shaped columns is then assessed. Finally, the effects of the embedding of the horizontal steel bars in the web (interior wall) in the core of the composite T-shaped joints on the earthquake resistant behavior of the composite Tshaped joints are studied.

\section{Tests}

\subsection{Sample design}

The plaster panels for the exterior walls of the composite T-shaped joints were integrated with thermal insulation systems in the factory. The dimensions of the plaster panels for the interior walls were as follows: the sides were $13 \mathrm{~mm}$ thick; the partitions were $20 \mathrm{~mm}$ thick and $160 \mathrm{~mm}$ high; the horizontal cavities were $94 \mathrm{~mm} \times 220 \mathrm{~mm}$; and the vertical cavities were $230 \mathrm{~mm} \times 94 \mathrm{~mm}$. The dimensions of the plaster panel systems for the exterior walls were as follows: the thermal insulation board was $120 \mathrm{~mm}$ thick; the plaster panel outside the thermal insulation board was $13 \mathrm{~mm}$ thick. The plaster panel systems for the exterior walls and the plaster panels for the interior walls were transported to the construction site to be assembled, reinforced, and poured with concrete. At the junction of the interior wall and exterior wall, some partitions were removed to form the core of the joint (hidden column), and steel bars were added based on the form of the column.

In order to study the connection between the interior and exterior plaster-based compound panels and the connector, a hidden T-shaped concrete column, at the core of the joint which was formed by connecting the interior plaster-based compound panel (web) and the exterior plasterbased composite panel (flange) using the connector by performing earthquake resistance tests on the joint under cyclic loading, two groups of samples, in each of which there were three samples, with the same dimensions were designed and tested using the same method. One group of samples were treated by embedding the horizontal steel bars embedded in the web (interior wall) and flange 
(exterior wall) of the samples in their core, called TJS samples, and the other group of samples were treated by not embedding horizontal steel bars embedded in the web (interior wall) and flange (exterior wall) of the samples in their core, called TJ samples. The plans of the TJS and TJ samples are shown in Figure 1 and Figure 2, respectively. The two groups of samples were numbered JS1, JS2, JS3, and J1, J2, J3, respectively. The composite T-shaped joint defined in this paper primarily consisted of the interior wall (web), the exterior wall (flange), the loading beam at the top, and the fixed beam at the bottom. The web consisted of the pure interior wall and the web of the core of the joint. The flange of the composite T-shaped joint consisted of the pure exterior wall, the flange of the core of the joint, and the external thermal insulation system of the flange of the core of the joint. The sectional dimensions of the loading beam at the top were $120 \mathrm{~mm} \times 220 \mathrm{~mm}$, and the sectional dimensions of the fixed beam at the bottom of the interior wall and the exterior wall were $270 \mathrm{~mm} \times 500 \mathrm{~mm}$ and $403 \mathrm{~mm} \times 500 \mathrm{~mm}$, respectively. The vertical reinforcements of the joint core were 16D14 and the structural stirrups were D6@150. In the joint non-core area, 1D14 reinforcement was vertically embedded in each vertical cavity, and 2D14 reinforcements were horizontally embedded in each horizontal cavity. Junctions of 3D14 horizontal reinforcements embedded in the loading beam with all the vertical reinforcements embedded in the interior wall were welded together, and their junctions with the stirrups in the core of each sample were bound together. 4D20 steel bars were horizontally embedded in the fixed beam at the bottom with $8 \mathrm{~mm}$-diameter stirrups installed at regular intervals of $200 \mathrm{~mm}$. Figure 3 and Figure 4 are the sections of the TJS and TJ samples.

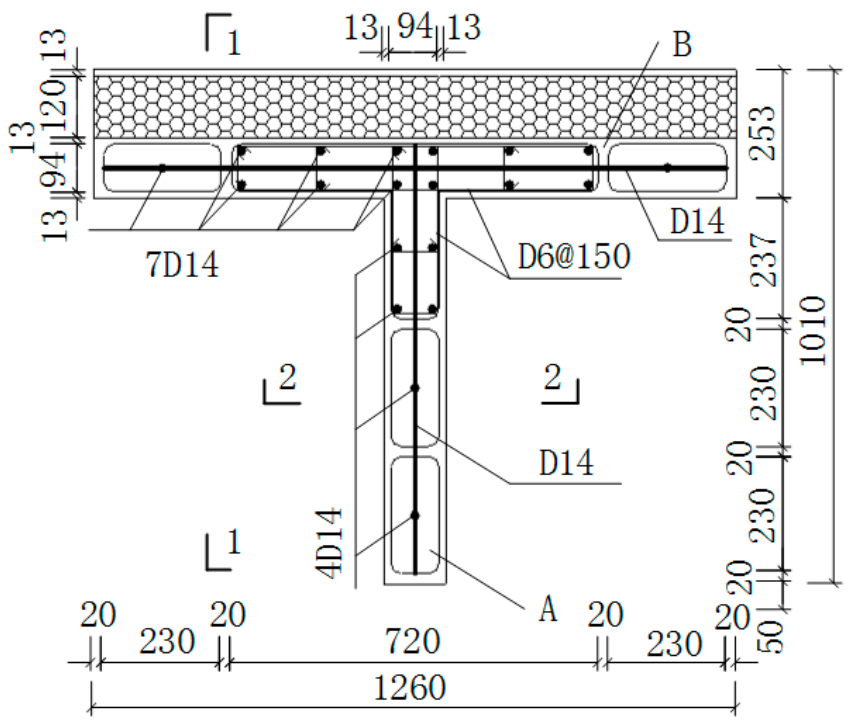

Figure 1. Plan of TJS (excluding the loading beam).

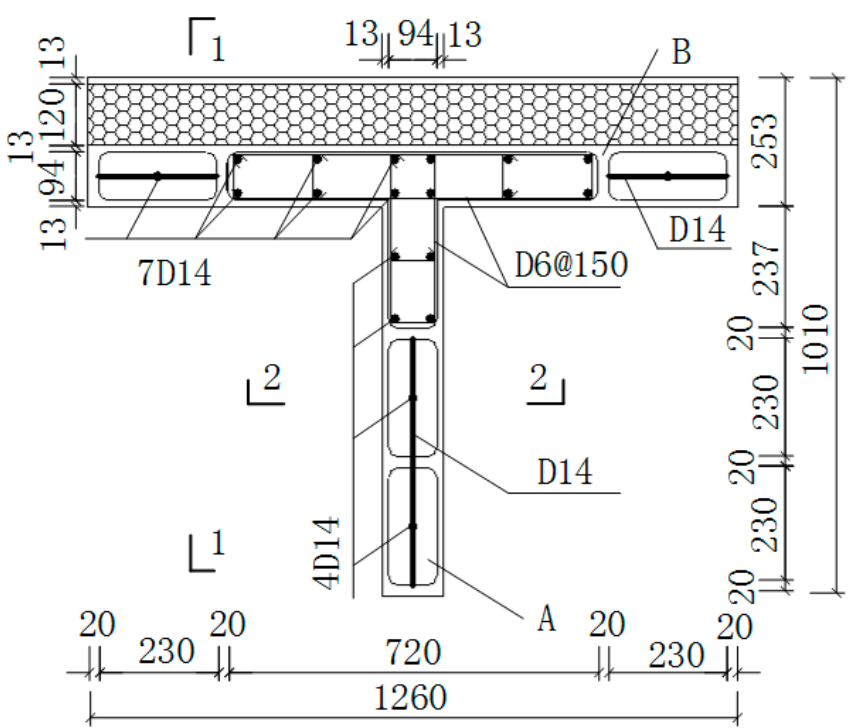


Figure 2. Plan of TJ (excluding the loading beam).

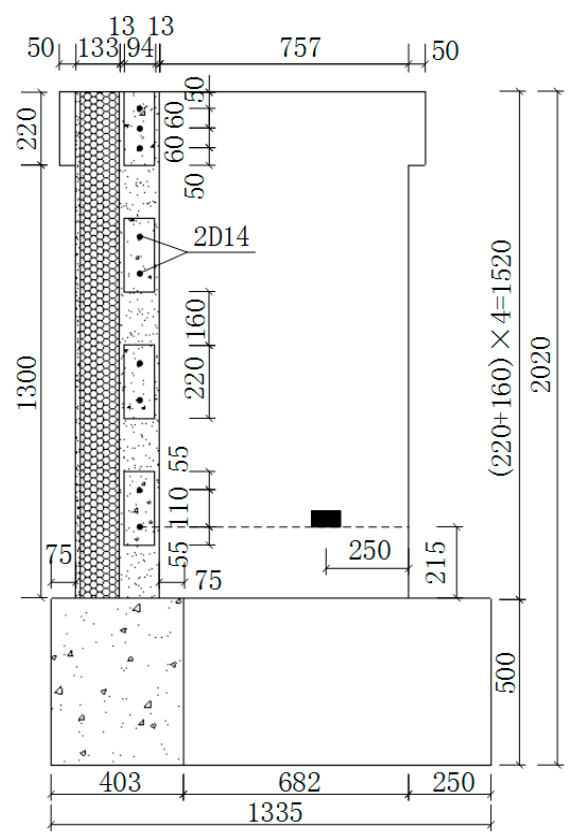

Figure 3. 1-1 section of the joints.

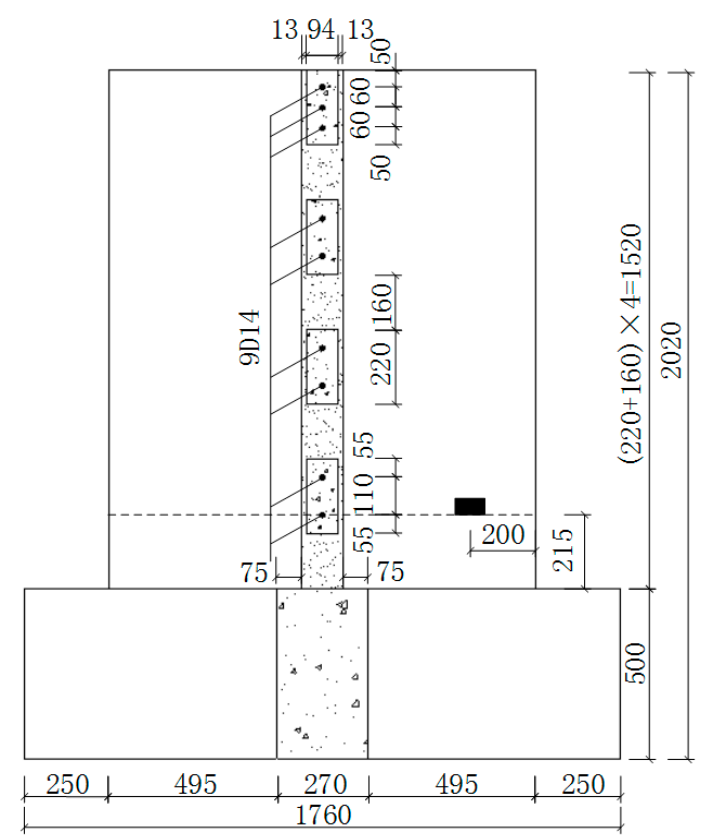

Figure 4. 2-2 section of the joints.

\subsection{Material properties}

Four $400 \mathrm{~mm}$ long steel bars of each type and three $150 \mathrm{~mm} \times 150 \mathrm{~mm} \times 150 \mathrm{~mm}$ concrete blocks in each batch were reserved during the production of the samples, and six polystyrene thermal insulation boards were selected and tested for the properties of the materials. The HPB300 steel was determined to have a tensile strength of 492.50 MPa (D6); the HRB400 steel was determined to have a tensile strength of 654.00 MPa (D8), 669.45 MPa (D14), and 676.92 MPa (D20) [15], respectively; the C20 concrete and polystyrene thermal insulation boards were determined to have compressive strengths of $24.63 \mathrm{MPa}$ and $206 \mathrm{kPa}$, respectively and elastic moduli of $2.72 \times 10^{4} \mathrm{MPa}$ and $2.3 \mathrm{MPa}$, respectively [16]. 


\subsection{Loading}

Each sample loaded horizontally and vertically in order to truly reflect the mechanical properties of the composite joints in actual engineering. In the vertical direction, three $50 \mathrm{kN}$ hydraulic jacks were used to apply a load to the rigid steel beam at the top of the sample in order to truly simulate the uniform passing of a load passed from the upper structure of a composite T-shaped joint to the joint and to avoid the effects of stress concentration. In the horizontal direction, a $1000 \mathrm{kN}$ push-andpull jack was placed against the top of the web of each sample to apply a reciprocating load in order to simulate the horizontal action of earthquakes. The push-and-pull jack was fixed to a reinforced concrete reaction wall at one end, and its other end was connected via a sensor to the loading beam fixed using two end steel plates and four rods. The jack gave a horizontal push to the web by pushing the end steel plate at the right side of the loading beam, and the end steel plate fixed at the other side of the loading beam gave a horizontal pull to the web by pulling the four rods. Each test was divided into preloading and loading. A load of not greater than $70 \%$ of the estimate of the cracking load of the sample was first applied to check whether all the apparatus operated normally, and the quasistatic test method defined in the specifications related to earthquake resistance tests was then used to test the sample under load controlled loading before yielding and displacement controlled loading after yielding. The loading system and test apparatus are shown in Figure 5.

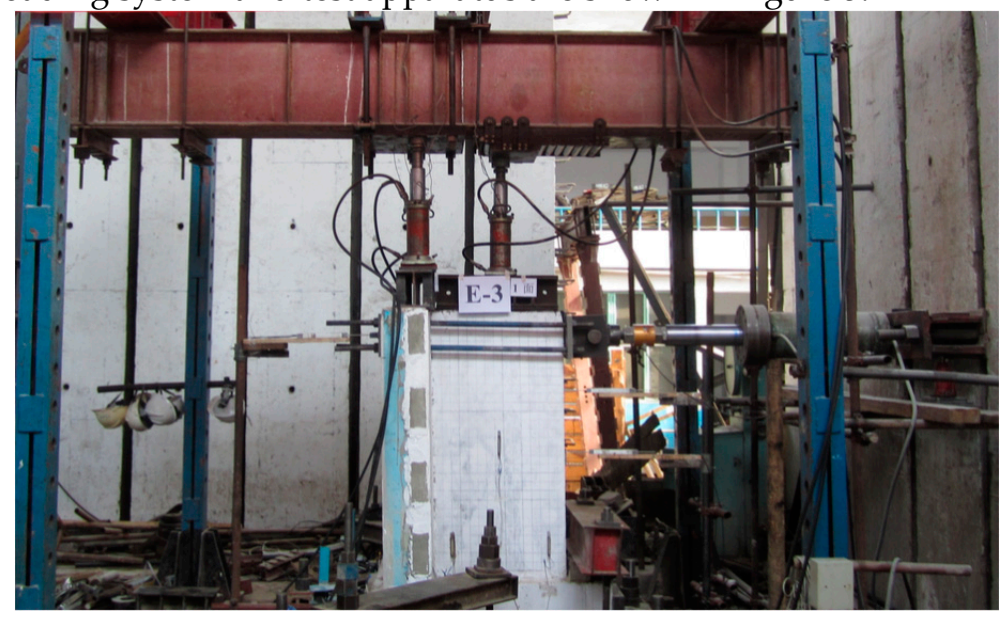

Figure 5. Loading system and test apparatus.

\subsection{Measurements and strain gauge placement}

The load applied to the top of the web of each sample was measured by the sensor connected between the horizontal jack and the sample and obtained by the acquiring device of the computer. The displacements at different heights were measured by the horizontal displacement meters placed on the sample. The formation and evolution of the cracks in the interior and exterior compound panels were observed in real time. Whether the fixed beam at the bottom of the sample displaced or not was determined by the dial indicator placed on the beam in order to eliminate errors. The strains in the steel bars, concrete, and plaster panels were determined by the strain gauges placed on the materials.

Experience reveals that failures would primarily occur in the middle to lower part of the samples. Therefore, strain gauges were placed in the crucial positions of the composite T-shaped joints as follows. 1. Plaster panels: SZ120-100AA paper based strain gauges were placed horizontally, vertically, and in the direction of $45^{\circ}$ in the middle (1/2 of the wall height and $1 / 2$ of the wall length) and lower parts ( $200 \mathrm{~mm}$ away from the side of the wall and $100 \mathrm{~m}$ away from the ground) of the flange and web of the samples; 2. Concrete: SZ120-60AA paper based strain gauges were placed vertically in positions corresponding to those for the plaster panels; 3. Steel bars: BQ120-10AA gum based strain gauges were placed along the direction of the length of the steel bars $100 \mathrm{~mm}$ away from the bottom of the vertical steel bars and $250 \mathrm{~mm}$ and $200 \mathrm{~mm}$ away from the outside edge of the horizontal steel bars embedded on the web and flange, respectively of the samples. Due to the limited 
length of this paper, only the positions of the strain gauges for the horizontal steel bars of the samples were shown in Figure 3 and Figure 4.

\section{Test phenomena description and failure modes}

Because the test phenomena and failure modes of the composite T-shaped joints of the same type were similar, typical samples, JS1 and J1, were selected for discussion.

\subsection{Initial cracking stage}

A preload of $\pm 30.00 \mathrm{kN}$ ("+" for positive loading, and "-" for reverse loading) was applied to each sample in order to ensure the smooth progress of the test. Sample JS1: When a load of +101.59 $\mathrm{kN}$ was applied to the sample, several horizontal cracks occurred in the right corner of the front of its web and stretched to the left corner, with the longest being about $600.00 \mathrm{~mm}$ long. Sample J1: When a load of $+100.75 \mathrm{kN}$ was applied to the sample, horizontal fine cracks also occurred in the right corner of the front of its web, with the longest being $400.00 \mathrm{~mm}$ long; the longest crack occurring in the left corner of the back of its web was $470.00 \mathrm{~mm}$. The two types of samples showed no significant difference in initial cracking; initial cracks occurred in the lower corner of both samples' web, and their flange showed no change.

\subsection{Crack evolution stage}

Sample JS1: When a load of $+150.55 \mathrm{kN}$ was applied to the sample, a number of $45^{\circ}$ cracks occurred in the center of the front of its web and stretched to the bottom of the web. Large areas of cracks occurred in the diagonal directions in the back of the web and tended to develop into main cracks. When a load of $+180.00 \mathrm{kN}$ was applied to the sample, the steel bars at the outside end of the pure interior wall yielded, and three $135^{\circ}$ cracks about $200.00 \mathrm{~mm}$ long occurred in the upper left corner of the web; the sample was about to be tested under displacement-controlled loading. Original cracks continued to evolve when the sample was displaced up to $\pm \Delta_{y}$ ( $\Delta_{y}$ stands for the yielding displacement) under loading. When the sample was displaced up to $+2 \Delta_{y}$, the inclined cracks in both sides of its web continued to evolve and widen, and the $45^{\circ}$ and $135^{\circ}$ cracks in its web intersected to form a dense network; several vertical cracks occurred in the front and back of its flange.

Sample J1: When a load of $+150.42 \mathrm{kN}$ was applied to the sample, three $45^{\circ} \mathrm{cracks}$ occurred in the center to lower right corner of the back of its web, which were $170.00 \mathrm{~mm}, 210.00 \mathrm{~mm}$, and $230.00 \mathrm{~mm}$, respectively. When a load of $+170.45 \mathrm{kN}$ was applied to the sample, the steel bars in the outside end of the pure interior wall yielded. When the sample was displaced up to $\pm \Delta y$, several new inclined cracks about $100.00 \mathrm{~mm}$ long occurred in the lower right corner of the front of the web, and some of the original cracks widened. When the sample was displaced up to $\pm 2 \Delta y$, a lot of short and fine cracks occurred in the area where the core of the sample connected with the pure interior wall; the horizontal cracks at the bottom of the flange increased and stretched, and some strain gauges failed.

The two samples differed greatly in terms of cracking. The cracks in the sample JS1 primarily occurred in the directions of $45^{\circ}$ and $135^{\circ}$ and the lower corner of the interior wall because the web and the hidden T-shaped concrete column were firmly connected via the horizontal steel bars and the weak area of the web primarily occurred in the lower corner of its outside end. The cracks in the sample J1 primarily occurred in the area where its core connected with the pure interior wall because the weak area of the web occurred in both the lower corner of the interior wall and the area where the web connected with the hidden T-shaped concrete column due to a lack of connection between the web and the hidden T-shaped concrete column provided by horizontal steel bars.

\subsection{Failures}

Sample JS1: When the sample was displaced $\pm 3 \Delta y$, some strain gauges for the steel bars, concrete, and plaster failed, and the cracks in the lower corner of its web widened considerably. When the sample was displaced $\pm 3.5 \Delta \mathrm{y}$, horizontal cracks occurred in the front and back of the flange, the 
concrete and plaster in the lower corner of the web were crushed or seriously cracked, and the steel bars were bent as shown in Figure 6(a), the vertical cracks on one side of the thermal insulation board of the flange ran through, and the horizontal load decreased to below $0.85 P_{y}$.

Sample J1: When the sample was displaced up to $\pm 3 \Delta y$, plaster at the junctions of the vertical cracks and the $45^{\circ}$ or $135^{\circ}$ cracks fell off. When the sample was displaced up to $\pm 3.5 \Delta y$, the vertical cracks in the web continued to widen; a new horizontal crack $680.00 \mathrm{~mm}$ long occurred in the center of one side of the thermal insulation board of the flange, horizontal cracks occurred in the middle to lower part running through the entire exterior panel, and the plaster in the cracks fell off. When the sample was displaced up to $-25.05 \mathrm{~mm}$ under loading, its displacement increased sharply, and the horizontal load was smaller than $0.85 P_{y}$.

The failure of the sample JS1 was reflected by the crushing or serious cracking of the concrete and plaster and the bending of the steel bars in the lower corner of the pure interior panel shown in Figure 6(a) and Figure 6(b), and the occurring of main $45^{\circ}$ cracks in the web (the core of the sample and the pure interior wall) shown in Figure 6(c). These two modes of failures belonged to the shear failure often found in component tests. The failure of the sample J1 was reflected by the occurring of a great number of inclined cracks in the web in the area where the core of the sample connected with the pure interior wall and the running through or widening of the vertical cracks shown in Figures Figure 6(d), Figure 6(e) and Figure 6(f); in other words, the sample J1 was unable to bear the heavy horizontal load and failed due to the separation of the core of the sample from the pure interior wall. The difference in the failure modes of the samples JS1 and J1 could be explained as follows. The horizontal steel bars embedded in the interior wall of the sample JS1 combined the interior wall and the core of the sample into a whole, which was conducive to the mechanics of the sample, while the area where the interior wall connected with the core of the sample J1 was weak. Overall, although the failures of the two samples were caused by the interior wall rather than the hidden T-shaped concrete column, the two samples differed in connection as reflected by the cracking and failure of the two samples.

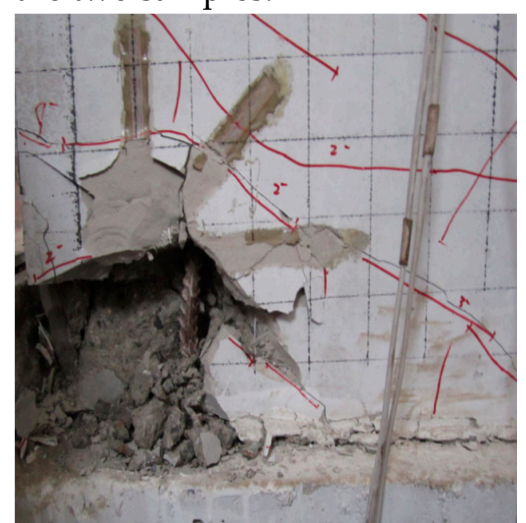

(a) JS1

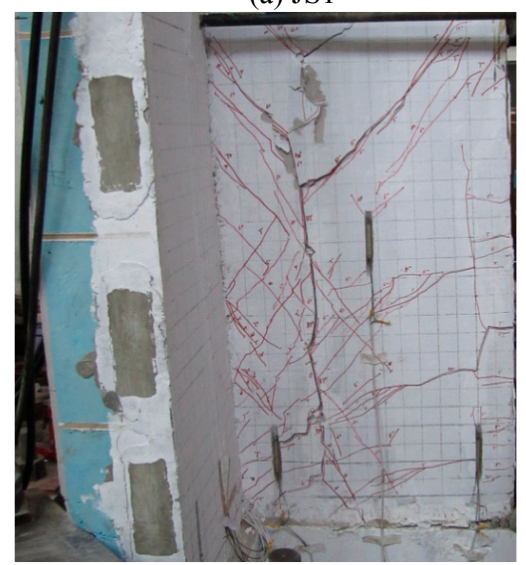

(d) J1

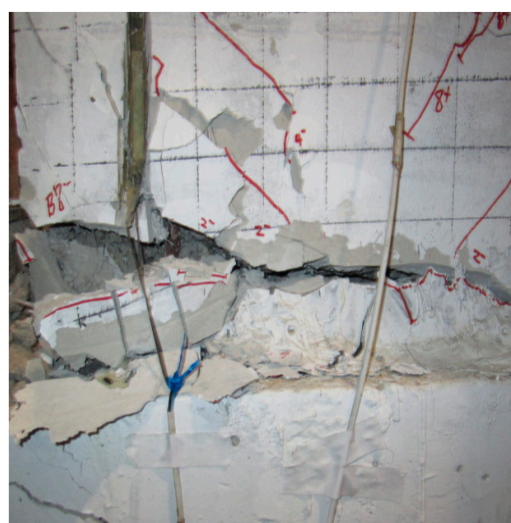

(b) JS2

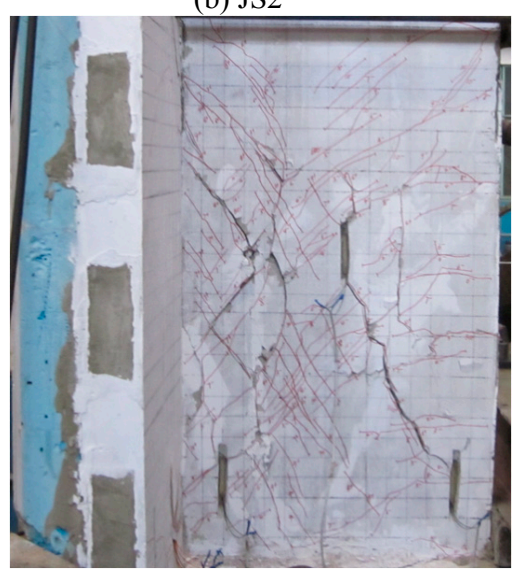

(e) $\mathrm{J} 2$

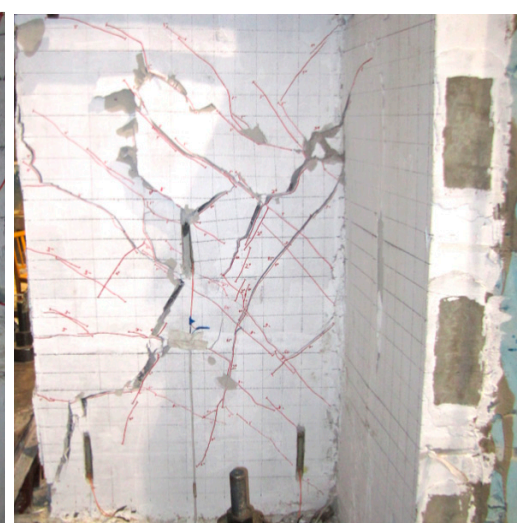

(c) JS3

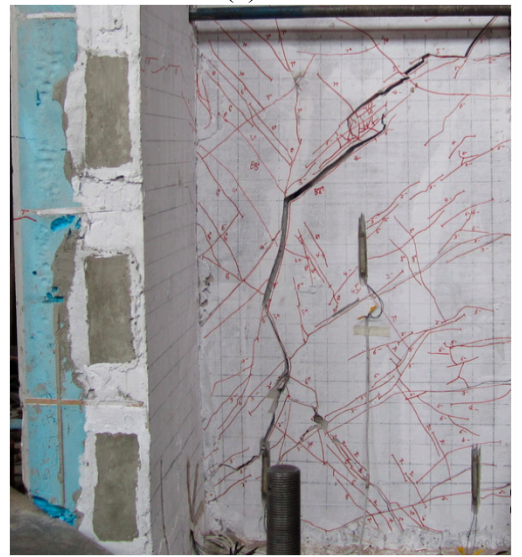

(f) J3

Figure 6. Failures. 


\section{The results and analysis}

\subsection{Hysteretic behavior}

The hysteresis curve of a composite T-shaped joint which describes the horizontal loadhorizontal displacement relationship of the joint under horizontal low-frequency cyclic loading can be used to assess the bearing, deformation, and energy dissipation properties of the joint [17]. The hysteresis and skeleton curves of the TJS and TJ samples are shown in Figure 7. Before the webs cracked, the two types of samples had small bearing capacity and small amounts of deformation; the hysteresis loops generally coincided for the same load, indicating that the samples were in the elastic stage where their residual deformation was almost zero and their stiffness also showed no change. The hysteresis loops for the various samples became increasingly full as the load was increased. According to the abscissae of the hysteresis curves for the samples shown in Figure 7, the deformation was not zero when the horizontal load was zero, indicating that the samples had entered the plastic stage, where their residual deformation increased gradually and stiffness degenerated increasingly seriously, from the elastic stage. The hysteresis curves for the TJS samples were significantly larger than those for the TJ samples, indicating that the energy dissipation capacity of the TJS samples was obviously stronger than that of the TJ samples.

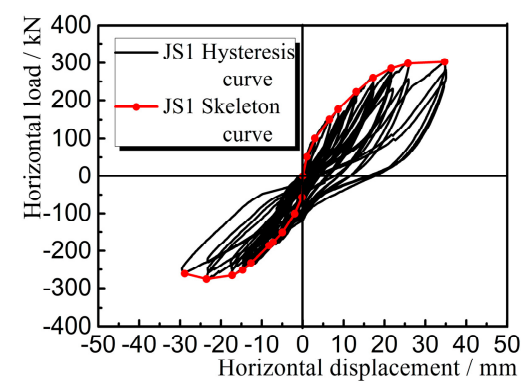

(a) JS1

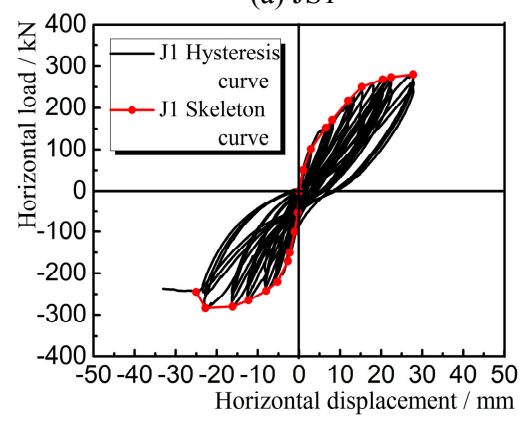

(d) $\mathrm{J} 1$

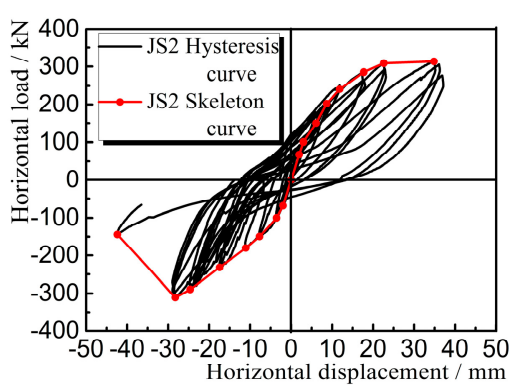

(b) JS2

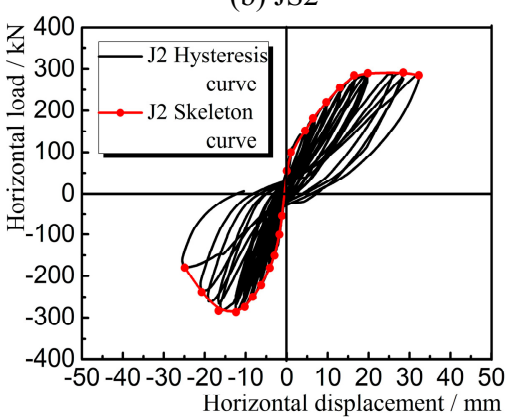

(e) $\mathrm{J} 2$

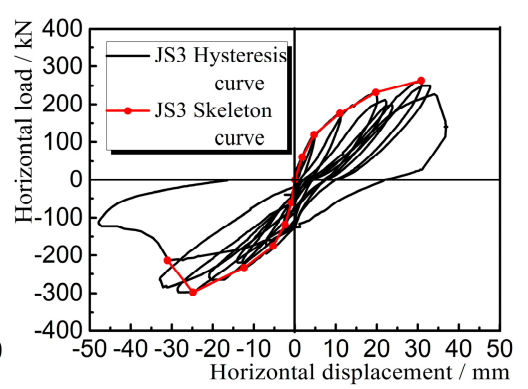

(c) JS3

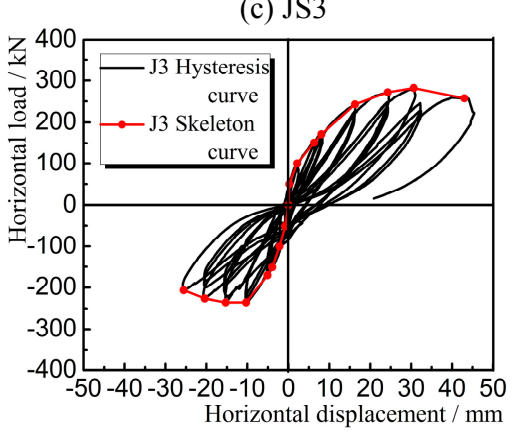

(f) J3

Figure 7. Hysteresis and skeleton curves.

\subsection{Skeleton curves}

Figure 8 shows a comparison of the skeleton curves obtained for the TJS and TJ samples. Before the webs of the samples cracked (the horizontal load borne by the TJS samples was lower than $30.99 \%$ of their ultimate load, and the horizontal load borne by the TJ samples was lower than 33.19\% of their ultimate load), their skeleton curves were generally linear, indicating that there was a linear relationship between their bearing capacity and their deformation. As the horizontal load was gradually increased, the webs of the samples got damaged increasingly seriously, and their skeleton curves changed from straight lines to curves. From a general point of view, the skeleton curves for the TJS samples were higher and longer than those for the TJ samples, indicating that the bearing and deformation properties of the TJS samples were superior to those of the TJ samples. As shown by the skeleton curves, the TJS and TJ samples suffered a sudden decrease in their bearing capacity, which was primarily due to the brittle failure of their webs. 


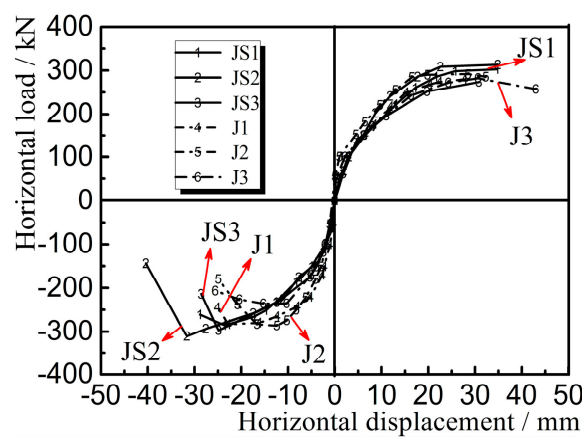

Figure 8. Comparison of the skeleton curves.

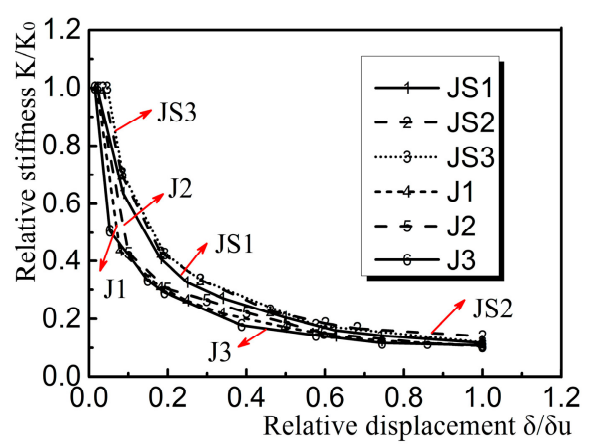

Figure 9. Stiffness degeneration curves.

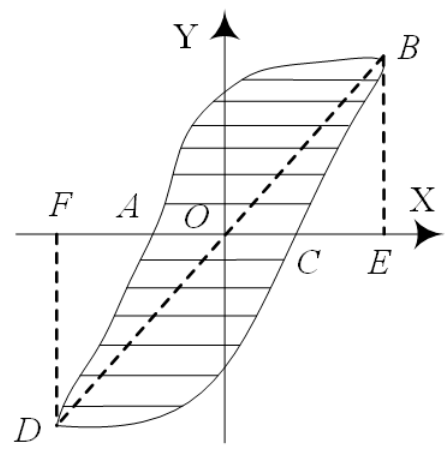

Figure 10. Energy dissipation diagram of the hysteresis loop.

\subsection{Ductility and bearing and deformation properties}

The displacement ductility factor $\mu$, which is the ratio of the ultimate displacement $\Delta u$, and the yielding displacement $\Delta y$, can be used to assess the earthquake resistance properties of composite Tshaped joints. The above parameters, the cracking load $P_{c r}$, the yielding load $P_{y}$, and the ultimate load $P_{u}$, were obtained using the methods suggested in the specifications related to earthquake resistance tests [18]. The angle of cracking displacement $\theta_{c r}$, the angle of yielding displacement $\theta_{y}$, and the angle of ultimate displacement $\theta_{u}$, were the ratios of the cracking displacement, the yielding displacement, and the ultimate displacement, respectively, to the effective height of the samples. The results obtained for the above parameters are shown in Table 1. The displacement ductility factors of the TJS and TJ samples were 3.76 and 3.80, respectively, which were almost the same, indicating that the ductility of the two types of joints was almost the same.

As shown in Table 1, the cracking loads of the two types of joints were almost the same, indicating that whether or not the horizontal steel bars in the web were embedded in the core of the joints had an insignificant effect on the initial cracking of the joints. The yielding loads and ultimate loads of the TJS samples were 1.07 times and 1.08 times on average, respectively greater than those 
of the TJ samples, indicating that embedding the horizontal steel bars in the web in the core of the joints can help improve the bearing capacity of the joints. The cracking displacements, yielding displacements, and ultimate displacements of the TJS samples were 1.21 times, 1.08 times, and 1.09 times on average, respectively greater than those of the TJ samples, indicating that the deformation properties of the TJS samples were superior to those of the TJ samples. A comparison of the angles of displacement recorded in Table 1 led to the same conclusion. This could be explained as follows. The TJS samples could bear a heavy load and large deformation due to the strong connection between their web and the concrete column provided by the embedded horizontal steel bars. The vertical cracks that occurred in the area where the web of the TJ samples and the hidden concrete column at their core connected without horizontal steel bars constantly increased and widened, thus leading to the early separation of the interior wall from the hidden concrete column at their core, which was responsible for the horizontal deformation of the TJ samples.

Table 1. Test results for samples.

\begin{tabular}{|c|c|c|c|c|c|c|c|c|c|c|c|c|c|c|c|}
\hline \multirow[b]{2}{*}{ Sample } & \multicolumn{4}{|c|}{ Cracking } & \multicolumn{5}{|c|}{ Yielding } & \multicolumn{5}{|c|}{ Ultimate } & \multirow{2}{*}{$\begin{array}{l}\text { Ductility } \\
\mu \text { Avg. }\end{array}$} \\
\hline & $P_{c r}$ Avg. & $\begin{array}{c}\Delta_{c r} \\
/ \mathrm{mm}\end{array}$ & Avg. & $\theta_{c r}$ & $\begin{array}{c}P_{y} \\
/ \mathrm{kN}\end{array}$ & Avg. & $\begin{array}{c}\Delta y \\
/ \mathrm{mm}\end{array}$ & Avg. & $\theta_{y}$ & $\begin{array}{c}P_{u} \\
/ \mathrm{kN}\end{array}$ & Avg. & $\begin{array}{c}\Delta u \\
/ \mathrm{mm}\end{array}$ & Avg. & $\theta_{u}$ & \\
\hline JS1 & 97.01 & 3.02 & & & 176.08 & & 8.63 & & & 302.71 & & 34.72 & & & 4.02 \\
\hline JS2 & 97.7395 .96 & 3.38 & 3.19 & $1 / 442$ & 186.95 & 179.35 & 8.35 & 8.34 & $1 / 169$ & 329.12 & 309.69 & 33.86 & 31.48 & $1 / 45$ & 4.063 .76 \\
\hline JS3 & 93.13 & 3.17 & & & 175.03 & & 8.04 & & & 297.25 & & 25.85 & & & 3.22 \\
\hline $\mathrm{J} 1$ & 93.69 & 2.74 & & & 161.81 & & 8.14 & & & 283.46 & & 27.77 & & & 3.41 \\
\hline $\mathrm{J} 2$ & 94.0194 .82 & 2.72 & 2.64 & $1 / 535$ & 173.36 & 167.85 & 6.36 & 7.69 & $1 / 183$ & 291.45 & 285.70 & 28.50 & 28.97 & $1 / 49$ & 4.303 .80 \\
\hline J3 & 96.76 & 2.45 & & & 168.39 & & 8.31 & & & 282.20 & & 30.63 & & & 3.69 \\
\hline
\end{tabular}

\subsection{Stiffness degeneration curves}

In earthquake resistance tests, the stiffness of composite T-shaped joints degenerates under horizontal cyclic loading, which is often explained by the decrease in the stiffness of composite Tshaped joints with the increase in the applied displacement-controlled load [19]. Typical points on the hysteresis curves for the TJS and TJ samples, namely the key points on the skeleton curves, were selected for study. The ratio of the ordinate (load) to coordinate (displacement) of the key points was expressed as the equivalent stiffness $K$ of the samples. $K$ o was defined as the initial stiffness of the samples, and $K / K_{0}$ was defined as the relative stiffness of the samples. Similarly, the ratio of the displacement corresponding to a key point to the maximum of the displacements corresponding to the key points was defined as the relative displacement $\delta / \delta_{u}$. The $K / K_{0}-\delta / \delta_{u}$ curves for the TJS and TJ samples are shown in Figure 9. As illustrated, the stiffness of the two types of joints decreased gradually, indicating that the two types of joints got damaged increasingly seriously with increasing and widened cracks under cyclic loading. The stiffness of the TJ samples degenerated more quickly than that of the TJS samples, especially in the elastic-plastic range, which was primarily caused by the vertical main cracks occurring in the area where the core of the TJ samples connected with the pure interior wall. This indicated that embedding the horizontal steel bars embedded in the web in the core of the joints can improve the lateral stiffness of the joints.

\subsection{Energy dissipation capacity}

Previous study results suggest that common specially shaped concrete columns have good properties [20-21]. The properties of hidden specially shaped concrete columns that combine with interior and exterior plaster-based walls require investigation into their energy dissipation capacity. Energy dissipation capacity is an indicator that is often used to assess the earthquake resistance properties of composite T-shaped joint under low-frequency cyclic loading. The fuller the area surrounded by a hysteresis loop, the stronger the energy dissipation capacity of the composite Tshaped joint [22]. The energy dissipation diagram of a typical hysteresis loop for the composite T- 
shaped joints is shown in Figure 10. The total area surrounded by the hysteresis loop $S_{A B C+C D A}$ was defined as the total energy dissipated by the composite T-shaped joint under a cycle of loading. From the two peaks, points $\mathrm{B}$ and $\mathrm{D}$, on the hysteresis loop, two lines vertical to the $\mathrm{X}$-axis were drawn, intersecting with the $\mathrm{X}$-axis at points $\mathrm{E}$ and $\mathrm{F}$. The peaks and points $\mathrm{E}$ and $\mathrm{F}$ were connected with the origin $\mathrm{O}$, respectively. The surrounded effective area $S_{B E O+D F O}$ represents the total energy dissipated by a linear elastic system that is the same as the composite T-shaped joint under a cycle of loading [23]. In earthquake resistance tests, the energy dissipation capacity of a composite T-shaped joint is often reflected by the equivalent viscous damping coefficient $h_{e}$ and the energy dissipation coefficient $E$ [24], which were studied respectively in the following.

\subsubsection{Equivalent viscous damping coefficient $h_{e}$}

The equivalent viscous damping coefficient $h_{e}$ of the composite T-shaped joints was calculated as $h_{e}=S_{A B C+C D A} /\left(2 \pi S_{B E O+D F O}\right)$. A greater $h_{e}$ value indicated a stronger energy dissipation capacity of the composite T-shaped joint. The $h_{e}$ results for the TJS and TJ samples were calculated as shown in Table 2. The equivalent viscous damping coefficient of the TJS and TJ samples were found to increase as their displacement increased. The $h_{e}$ of the TJS and TJ samples for three times of the yielding displacement were 1.71 times and 1.83 times, respectively of that for one time of the yielding displacement, indicating that the energy dissipation capacity of the two types of joints increased constantly. The equivalent viscous damping coefficient of the TJS samples was 1.09 times greater than that of the TJ samples for three times of the yielding displacement, indicating that the joints of interior and exterior compound panels have stronger earthquake resistance and energy dissipation capacity than common concrete joints, and that the TJS samples have stronger earthquake resistance and energy dissipation capacity than the TJ samples.

\subsubsection{Energy dissipation coefficient $E$}

The energy dissipation coefficient $E$ is often used to measure the energy dissipation capacity of a composite T-shaped joint under cyclic loading. As provided for in the Specification of Testing Methods for Earthquake Resistant Building, $E$ is calculated as $E=S_{A B C+C D A} / S_{B E O+D F O}$ [18]. The results calculated for the TJS and TJ samples are shown in Table 2. When the samples were displaced $1 \Delta_{\mathrm{y}}$, $2 \Delta_{\mathrm{y}}$, and $3 \Delta_{\mathrm{y}}$, the $E$ for the TJS samples were $0.44,0.50$, and 0.75 , respectively, and that for the TJ samples were $0.38,0.57$, and 0.69 , respectively, which could lead to the conclusions that the energy dissipation coefficient $E$ of the two types of joints increased as their displacement increased and that the TJS samples have better earthquake resistance properties than the TJ samples.

Table 2. Energy dissipation and power ratio coefficients.

\begin{tabular}{|c|c|c|c|c|c|c|c|c|c|c|c|c|}
\hline \multirow{2}{*}{ Sample } & \multicolumn{5}{|c|}{ Viscous damping coefficient $h_{e}$} & \multicolumn{3}{|c|}{ Dissipation coefficient $E$} & \multicolumn{4}{|c|}{ Power ratio coefficient $I_{W}^{S}$} \\
\hline & $1 \Delta \mathrm{y}$ & Avg. & $2 \Delta y$ Avg. & $3 \Delta y$ & Avg. & $1 \Delta \mathrm{y}$ & $2 \Delta y$ & $3 \Delta y$ & $1 \Delta y$ Avg. & $2 \Delta y$ & Avg. $3 \Delta y$ & Avg. \\
\hline JS1 & 0.08 & & 0.08 & 0.09 & & & & & 1.00 & 3.94 & 9.00 & \\
\hline JS2 & 0.07 & 0.07 & 0.080 .08 & 0.13 & 0.12 & 0.44 & 0.50 & 0.75 & 1.001 .00 & 3.49 & 3.627 .21 & 8.32 \\
\hline JS3 & 0.07 & & 0.09 & 0.15 & & & & & 1.00 & 3.92 & 8.25 & \\
\hline $\mathrm{J} 1$ & 0.05 & & 0.08 & 0.10 & & & & & 1.00 & 3.98 & 8.45 & \\
\hline $\mathrm{J} 2$ & 0.05 & 0.06 & 0.090 .09 & 0.10 & 0.11 & 0.38 & 0.57 & 0.69 & 1.001 .00 & 3.87 & 3.888 .75 & 8.14 \\
\hline J3 & 0.08 & & 0.11 & 0.12 & & & & & 1.00 & 3.82 & 8.54 & \\
\hline
\end{tabular}

\subsubsection{Power ratio coefficient $\boldsymbol{I}_{W}^{S}$}

The power ratio coefficient $I_{W}^{s}$, which is often used to assess the energy dissipation properties of a composite T-shaped joint [14], was calculated as $I_{W}^{S}=\sum_{i=1}^{n} P_{i} \delta_{i} / P_{y} \delta_{y}$ [15]. The $I_{W}^{S}$ results for the two types of joints were calculated as shown in Table 2. The $I_{W}^{S}$ of the TJS and TJ samples were found to increase as their bearing capacity and deformation increased. The $I_{W}^{S}$ of the TJS and TJ samples for 
twice of the yielding displacement were 3.62 times and 3.88 times, respectively greater than that of the TJS and TJ samples for one time of the yielding displacement, and that of the TJS and TJ samples for three times of the yielding displacement were 8.32 times and 8.14 times, respectively greater than that of the TJS and TJ samples for one time of the yielding displacement, indicating that the joints exhibited increasingly strong energy dissipation capacity after yielding. The $I_{W}^{S}$ of the TJS samples was 1.02 times greater than that of the TJ samples for three times of the yielding displacement, indicating that embedding horizontal steel bars in the core of the joints can improve the energy dissipation capacity of the joints.

\subsection{Strain analysis}

The strains of the horizontal steel bars embedded in the web of the two types of joints were compared as shown in Figure 11. The averages of the strains of the horizontal steel bars embedded in the web of the three TJS samples under their horizontal ultimate load were $456.28 \mu \varepsilon$ and $449.45 \mu \varepsilon$ (reverse), respectively, 3.02 times and 2.91 times (reverse) (2.97 times on average), respectively greater than those of the horizontal steel bars embedded in the web of the TJ samples under their horizontal ultimate load, which were $151.06 \mu \varepsilon$ and $154.59 \mu \varepsilon$ (reverse), respectively. This indicated that the horizontal steel bars embedded in the web (interior wall) of the TJS samples bore a higher load than those of the TJ samples.

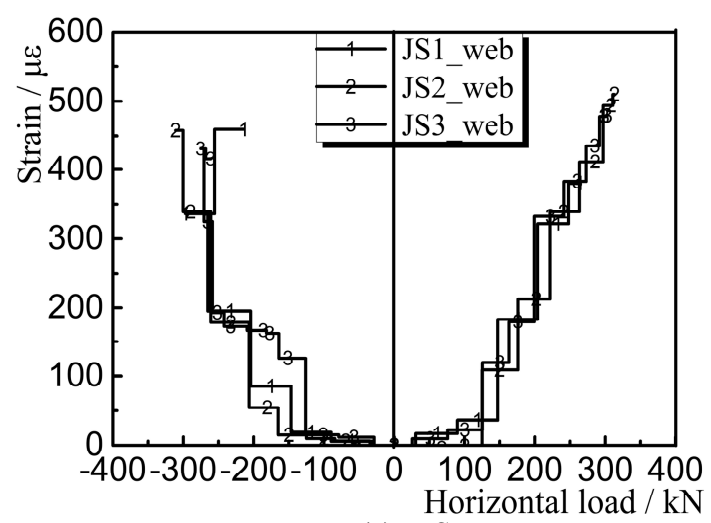

(a) TJS

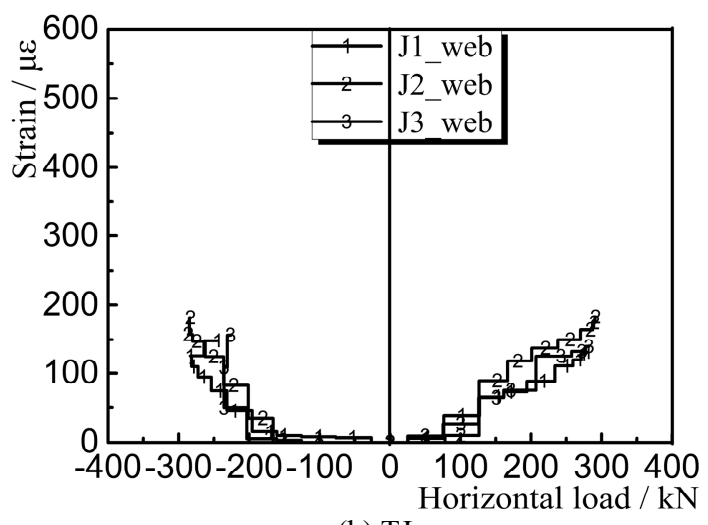

(b) $\mathrm{TJ}$

Figure 11. Horizontal load-steel bars strain curves (web).

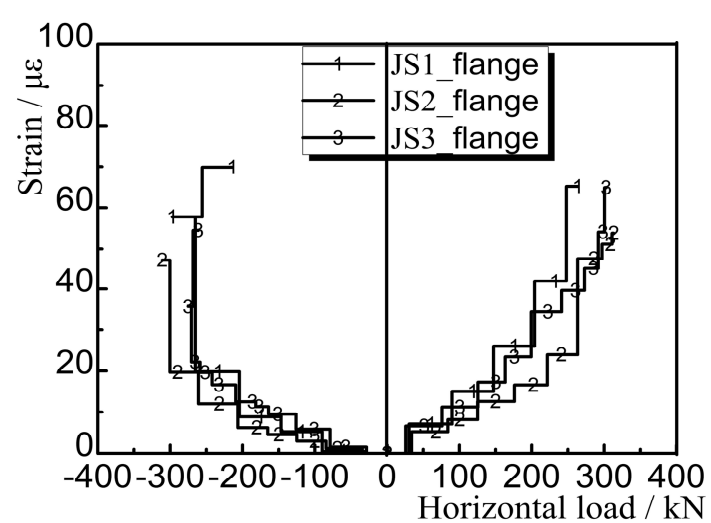

(a) TJS

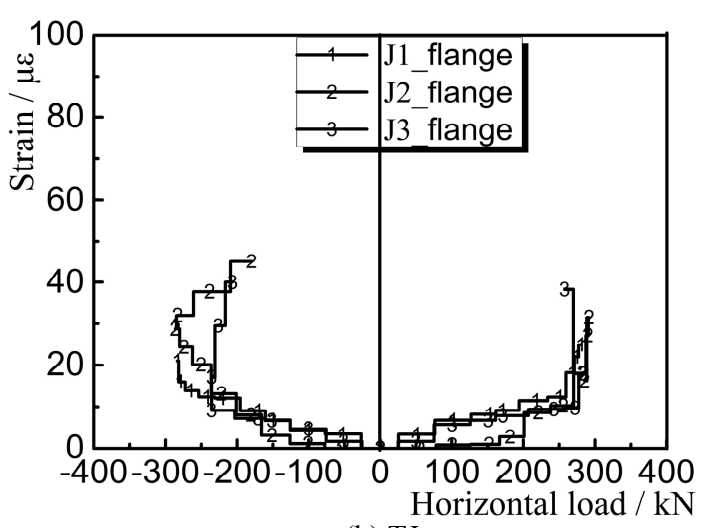

(b) TJ

Figure 12. Horizontal load-steel bars strain curves (flange).

The strains of the horizontal steel bars embedded in the flange of the two types of joints were compared as shown in Figure 12. Similarly, the averages of the strains of the horizontal steel bars embedded in the flange of the TJS samples under their ultimate load were $61.30 \mu \varepsilon$ and $50.93 \mu \varepsilon$ (reverse), respectively, 1.94 times and 1.85 times (1.90 times on average), respectively greater than those of the horizontal steel bars embedded in the flange of the TJ samples, which were $31.55 \mu \varepsilon$ and 
$27.50 \mu \varepsilon$ (reverse), respectively. This also indicated that the steel bars embedded in the core of the joints bore a stronger force than those not embedded in the core of the joints.

The strains of the horizontal steel bars embedded in the web of the samples were found to be significantly greater than those of the horizontal steel bars embedded in the flange of the samples, indicating the web (interior wall) of the samples contributed more to bearing the horizontal load than their flange did. The interior plaster-based compound panel delivered poorer performance than the hidden reinforced concrete column, which also explained why the failures of the samples were primarily caused by the web.

\subsection{Ability assessment of T-shaped columns}

The maximum shear force that the T-shaped column at the core of the samples can bear was calculated according to the Technical Specification for Concrete Structures with Specially Shaped Columns [25].

Without regard to earthquake effects: $V_{c}=1.75 f_{t} b_{c} h_{c 0} /(1+\lambda)+f_{y v} A_{s v} h_{c 0} / s+0.07 N$

With regard to earthquake effects: $V_{c}^{\prime}=\left[1.05 f_{t} b_{c} h_{c 0} /(1+\lambda)+f_{y v} A_{s v} h_{c 0} / s+0.056 N\right] / \gamma_{R E}$

In these equations, $\lambda$ represents the shear span ratio, $f_{t}$ represents the tensile strength value measured through the material tests on concrete, $b_{c}$ represents the thickness of the section of the leg of the T-shaped column, $h_{c 0}$ represents the effective height of the section of the leg of the T-shaped column, $f_{y v}$ represents the tensile strength value of the stirrups installed around the concrete column measured through the material tests, $A_{s v}$ represents the sum of the sectional areas of the legs of the stirrups installed around the concrete column, $s$ represents the regular intervals between the stirrups installed around the T-shaped column, and $N$ represents the design value of axial pressure [26].

As calculated, $V_{c}=372.09 \mathrm{kN}$, and $V_{c}^{\prime}=349.38 \mathrm{kN}$. The averages of the horizontal ultimate bearing capacity values of the TSJ and TJ samples obtained through the tests were $309.69 \mathrm{kN}$ and $285.70 \mathrm{kN}$, respectively, indicating that the TJS samples did not display $16.77 \%$ and $11.36 \%$ of their bearing capacity, and that the TJ samples did not display $23.22 \%$ and $18.23 \%$ of their bearing capacity. These data fully showed that it is reliable to use a T-shaped column at the core of the joints, which provides a larger safety reserve and reinforces the joints, and that it is important to connect the core of the joints with the compound panels via the horizontal steel bars in the compound panels.

\section{Conclusion}

Earthquake resistance tests were performed on two types of joints under cyclic loading to analyze their mechanical deformation, cracking, failure modes, hysteretic behavior, ductility, stiffness degeneration, and energy dissipation properties such as damping coefficient, energy dissipation coefficient, and power ratio coefficient. The results indicated that the TJS samples had better earthquake resistance properties than the TJ samples.

In the initial cracking stage of the tests, cracks occurred in the lower corners of the web (interior wall) of the two types of joints, and their flange (exterior wall) showed no significant change. In the crack evolution stage, the cracks in the TJS samples were mostly distributed in the lower corners of the web and in the directions of $45^{\circ}$ and $135^{\circ}$, and the cracks in the TJ samples were primarily distributed in the area where their core connected with their web (interior wall). In the failure stage, the concrete and plaster in the lower corners of the web of the TJS samples were crushed and cracked, or large cracks occurred in the web in the direction of $45^{\circ}$, which belonged to common shear failure, and large vertical cracks occurred in the area where the core of the TJ samples connected with their interior wall.

The bearing and deformation properties of the TJS samples were found to be superior to those of the TJ samples. The cracking, yielding, and ultimate displacements, equivalent viscous damping coefficients, and power ratio coefficients of the TJS samples were 1.21 times, 1.08 times, 1.09 times, 1.09 times, and 1.02 times, respectively greater than those of the TJ samples, which indicated that 
embedding the horizontal steel bars in the compound panels in the T-shaped column can effectively improve the earthquake resistance of the joints.

The hidden T-shaped columns still reserved some shear capacity after the failures of the joints, indicating the reliability of using a T-shaped column at the core of the joints, which provides a large safety reserve and reinforces the joints.

Acknowledgments: The authors would like to acknowledge the financial support of the National Natural Science Foundation of China (51478312), and Science Technology of the Ministry of Housing and Urban-Rural Development (2013-R4-25).

Author Contributions: Shaochun Ma performed the tests, analyzed the data and wrote the paper. Nan Jiang conceived and supervised the work. All authors contributed to conclusion.

Conflicts of Interest: The authors declare no conflict of interest.

\section{References}

1. Li W.B.; Liu Y.S. The revelation of LEED toward Chinese green building evaluation criteria. Railway Standard Des. 2015, 59(8), 169-174.

2. Wu P.; Liang Z.Q.; Lv X.J. Progress of research on cementitious property and activation of steel slag powders. China Powder Sci. Technol. 2015, 21(4), 80-84.

3. Huang W. Industrial by-product gypsum used in building materials. Master thesis, Tianjin University, PRC, 2010

4. Chinese National Standards. Load Code for the Design of Building Structures. GB50010-2010, Beijing, China, 2012.

5. Wang Q.M.; Ma K.J.; Li C.; Duan X.K. New ways of industrial gypsum in building projects. Sichuan Build. Sci. 2015, 41(1), 243-246.

6. Hao M.P. Prospect of applications of glass fiber products and composites in construction. Fiber Glass 2015, 4, 7-14.

7. Liu K.; Wu Y.F.; Jiang X.L. Shear strength of concrete filled glass fiber reinforced gypsum walls. Mater. Struct. 2008, 41, 649-662.

8. Janardhana M.; Prasad A.M.; Menon D. Studies on the behavior of glass fiber reinforced gypsum wall panels. Proceedings of the 8th U.S. national conference on earthquake engineering, April 18-22, 2006, San Francisco, California, USA, paper no. 1326. 2006.

9. Maganti, J.; Robin, D.P.; Ravichandran, S.S. Calibration of a hysteretic model for glass fiber reinforced gypsum wall panels. Earthq. Eng. Eng. Vib. 2014, 13, 347-355.

10. Elisa Poletti; Graça Vasconcelos; Marco Jorge. Application of near surface mounted (NSM) strengthening technique to traditional timber frame walls. Constr. Build. Mater. 2015, 76, 34-50.

11. Pozza L.; Scotta R.; Trutalli D. Behaviour factor for innovative massive timber shear walls. Bull. Earthquake Eng. 2015, 13, 3449-3469.

12. Jiang N.; Ma S.C. Simplified calculation model and experimental study of latticed concrete-gypsum composite panels. Materials 2015, 8, 7199-7216.

13. Jiang X.L.; Nie Q.L.; Zhang Y.L.; Gu Y. Experimental research on the L-shape connection specimens made of fiber-reinforced plasterboard. Ind. Const. 2005, 35(7), 67-70.

14. Jiang X.L.; Zhang Y.L.; Nie Q.L.; Gu Y. Experimental research on the seismic performance of fiberreinforced plasterboard filled with reinforced concrete joints under low cyclic loading. Earthq. Eng. \& Eng. Vib. 2004, 24(5), 149-53.

15. Ma S.C.; Jiang N. Seismic experimental study on new-type composite exterior wallboard with integrated structural function and insulation. Materials 2015, 8, 3732-3753.

16. Ma S.C.; Jiang N. Experimental investigation on the seismic behavior of a new-type composite interior wallboard. Mater. Struct. 2016, DOI: 10.1617/s11527-016-0845-1.

17. Sun G.H.; Gu Q.; He R.Q.; Yu Y.Q.; Fang Y.Z. Experimental study on steel frame with RC infill walls and flushed end-plate connections. J. Xi'an Univ. Arch. \& Tech. 2010, 42(1), 28-35.

18. Chinese National Standards. Specification of Testing Methods for Earthquake Resistant Building. JGJ101-96, Beijing, China, 1997.

19. Tang J.R. Seismic behavior of reinforced concrete frame joint. Dongnan University Press, Nanjing, China, 1989. 
20. Jie X.; Zhang J.X.; Li Y.Y. Improvement measure on aseismic behabior of specially shaped column joints under cycle loading. Eng. Mech. 2015, 32(8), 58-65.

21. Cao W.L.; Wu H.P.; Dong H.Y.; Zhang J.W. Research and application of mega-frame structure with specialshaped columns. J. East. China Jiaotong Univ. 2015, 32(1), 1-8.

22. Fan Y.F.; Cao W.L.; Zhang J.W.; et al. Experimental study on seismic behavior of high RC shear wall with concealed steel truss under axial-load ratio. World Earthq. Eng. 2007, 23(3),18-23.

23. Tan Y.H.; Liu W.J.; Jiang H.; Liu F.H. Experimental on steel beam and concrete wall joint under low reversed cyclic loading. Build. Struct. 2011, 41(1), 6-10.

24. Kwan A.K.H. Local deformations and rotational degrees of freedom at beam-wall joints. Comput. Struct. 1993, 48(4), 615-625.

25. Chinese National Standards. Technical Specification of concrete structures with specially shaped columns. JGJ1492006, Beijing, China, 2006.

26. Li Q.L.; Zhang X.H.; Zheng S.D.; Liu C.H. New ideas with predicted shear capacity of T shaped column. J. Hebei Univ. Agric. 2011, 34(5), 104-108.

(C) 2016 by the authors; licensee MDPI, Basel, Switzerland. This article is an open access article distributed under the terms and conditions of the Creative Commons by Attribution (CC-BY) license (http://creativecommons.org/licenses/by/4.0/). 